\title{
The American Way of Family Education in Boyhood and the Enlightenment to China
}

\author{
Liu Yan \\ Canvard College, Beijing Technology and Business University, No. 1 Song Zhuang Nan Lu, Tong \\ Zhou Dist, Beijing, China \\ liuyan_662003@163.com
}

Keywords: Boyhood, American Family Education, Enlightenment to Chinese Family Education.

\begin{abstract}
Richard Stuart Linklateris an American independent film director and scenarist. It takes almost 12 years for him to make a feature film called Boyhood, which mainly talks about a little boy Mason's growth experiences from 6 to 18 years old. Throughout the film, American parents' educational methods to their growing children can be regarded as a model of concepts of family education, from which our Chinese parents should learn. Democracy,independence,respects and interests are the keywords in this movie.Parents should respect children's personality and talent, trust them, listen to children patiently and entitle them more autonomy. Paying attention to and encouraging them to think independently are equally essential to the children. Based on the examples and analysis from this movie, the paper finds out advantages of American family education,which will cast enlightenment on Chinese family education.
\end{abstract}

\section{Introduction}

Feature Film is a kind of film which adapts events that happen in real life for the screen. Without intense fight scenes, amorous activities and funny punch lines, it focuses on plots and goes at a slow pace. Feature Films frequently mirror a social phenomenon or certain groups of people so that the story can easily resonate emotionally with audience. The movie Boyhood is a feature film which is written and directed by Richard Linklater. After taking 12 years from 2002 to 2014, the film premieres on July $18^{\text {th }}, 2014$. It tops the $72^{\text {nd }}$ annual Golden Globes Awards with Best Picture, Best Director and Best Actress. At the same time, it wins a Silver Bear for Best Director at Berlin International Film Festival.

The film shows brand-new things on family relationship, love and education to Chinese audience, which brings us some peculiar cognition for which we enjoy the film patiently. Boyhood tells stories of a little boy Mason's 12 years growth experiences and life changes of his parents. Factors of growth, years, maturity, education, life and love enable the film to have much more worth-seeing. Mason, who had experienced parental divorce, moved with his mother for several times and transferred to different schools. Mason's mother Olivia went into many places with two children, and went for further study while making a living. She was an independent mother, even though her several marriages ended up with divorces. Mason's father Ted didn't have a stable job, but he loved music and advocated spiritual freedom. He paid more attention to freedom of children, and focused on cultivating children's independent character. Wherever Olivia and the children moved to, Mason's father insisted on spending weekends with his children every two weeks. He was Mason's spiritual guide. Mason's sister Samantha, who was a rebellious girl, grew up with Mason all along.

\section{Analysis of American Family Education in Boyhood}

\subsection{Relationship between Parents and Children}

2.1.1 Equal Relationship between Parents and Children. Family education is centered on the parent-child relationship, while the parentage is also a vital factor which restricts family education. American culture emphasizes individual rights and freedom. Parents should be teachers rather than rulers of children [1].American parents usually regard children as independent units, and communicate with them as friends. When children make mistakes, parents often patiently and 
politely reason them out of bad behaviors. For example, at the very beginning of Boyhood, when Mason's mother Olivia knew that her 6 years old son Mason didn't finish homework and broke the teacher's pencil sharpener, she didn't teach him a lesson immediately, instead, she talked with Mason like a friend to find out the reasons and her son's thought about it. The truth was that Mason thought sharpen pencils maybe could sharpen rocks. Children sometimes make mistakes just because they want to make out new ideas.

2.1.2Democratic Relationship between Parents and Children. American parents respect ideas of children, and let children decide their own affairs. They support children's ideas and never make them do what they are not interested in. Thus there are usually democratic relationships between American parents and children [2]. For some American parents, children are not "things", but independent persons, so that they usually create democratic environment to get along with their children and help them improve capability of thinking independently. In the film, we can see Mason's father Ted often discussed politics, pop music, movies, friendship and even romance with his children, from which we feel that American children have enough courage to tell their parents their own ideas in the relaxed and pleasant atmosphere. When Mason and Samantha went for weekends with their father for the first time, Ted even talked with his children about private emotional problems. Ted respected his children all the time, and often asked the children to support him in a negotiable tone. However, the father got fined when he spoke dirty words in front of the children. When children asked about emotional problems between him and their mother, the father answered Samantha's questions patiently.

\subsection{Concepts of American Family Education}

2.2.1 Regard Children as Independent Person. American culture advocates freedom, which deeply affects American family education. In this type of family education, American families regard children as independent persons being equal to parents. When the families make big decisions, they always respect children's opinions. For children, parents are friends rather than rule makers [3].For example, sometimes, Mason just called old Mason by his first name "Ted". As a high school student, Mason worn earrings and nail polish. After knowing this, Olivia preferred to ignore the problems, rather than interfere with. American parents insist to give children rights to make decisions. They firmly believe that only by making own decisions, can children develop individual value and independent character. American parents point right directions for children, but they seldom make decisions for children, let alone impose their wishes on their children. In their eyes, children have the ability to tell right from wrong.

2.2.2Pay Attention to Children's Individual Development. American parents pay more attention to all-round developments of children, and they seldom focus on academic record, and will not punish them for test scores. For example, the sister Samantha was better at studying than Mason who liked playing computer games. However, his parents never compared them with each other or made Mason study harder. At the same time, we can find that Ted attached great importance to children's ideas of freedom and democracy. Ted played with his children as if he were their friends. When Ted knew the 15 years old Samantha had a boyfriend, he felt surprised and happy. He also worried about her so that he told her the importance of contraception, and hoped that she could avoid getting pregnant before 17. Thus it can be seen that Mason's father really treated his children as individual persons. In this kind of environment, children can share their inner world with parents better.

\subsection{Mode of American Family Education}

2.3.1Cultivate the Independence and Adaptability of Children. The purpose of American parents to cultivate children is to make them have the ability to adapt to all kinds of environments. American parents bring up their kids without indulgence but freedom to train their self-independence. For example, since Mason and Samantha were little kids, their mother had already let them sleep alone during the night without accompanying. When they moved, Mason helped his mother do some whitewashing and moving. Mason and Samantha needed to do some housework at an early age. And when Mason became a high school student, his mother allowed him to work outside to make money which can not only contribute to building up the concept of labor, 
but also training their self-independence. Only put him in the labor can he realize how hard to make money so as to develop the good habit of thrift. Mason and Samantha grew up with a place to store personal clothing. They tidied up their own room, decorated their own tiny world .American parents never arrange for them but do some reminding at most.

2.3.2Educate Children by Encouraging. The core of American family education is appreciation. The parents often praise and encourage their children which can help children build up self-esteem, self-confidence and self-worth. In the movie, when the father Ted got together with his children, he often used "Awesome", "That's good", "Come on", "You can get it", etc. to encourage them. For example, there was a scene that Ted wanted to go bowling with Mason and Samantha, we can clearly see and realize that the encouragement and belief from Mason's father permeated in the whole dialogue. Although Mason missed every ball, his father still encouraged him and felt proud of him.

2.3.3Respect Interests of Children. American parents pay great attention to children's choices on hobbies and interests. They perceive that parents shall never force children to do things when they are not interested in or can't understand. Parents shall show respect as long as those hobbies are valid. This is because children can develop their creativity and potential when doing their interested things. Moreover, their concentration, graveness, the habit to preserve and volition can be practiced which are beneficial to their growth. In the movie, the protagonist Mason adored photographing, which was supported by his parents and teachers. On his $15^{\text {th }}$ birthday, his stepfather bought a camera as gift for support. Eventually, Mason had won silver prize in photographing competition before entering university, which helped him apply for the scholarship. These have fully demonstrate that when children present great interests in certain areas, their creativity and potential can be developed and finally achieve surprising accomplishments.

\section{The Enlightenment to Chinese Family Education.}

3.1 Cultivate Independent Personality. Biological father and mother of Mason never restrained his ideas and personality, and they paid attention to his potential personality and creativity. As we have seen from the film, Mason had a childhood which is different from that of Chinese children, he had a lot of time to play his favorable games, watched anime, rode a bike and doodled with his friends. Olivia didn't register various supplementary classes for Mason to occupy his playtime. Chinese parents are used to comparing children by one standardized criteria and ignoring children's potential, which greatly stifles children's personality and hobbies. As parents, we should carry out individualized education based on children's talent and personality. Moreover, parents should respect children's dream and choice, permit them to develop freely and make them be full of creative ideas and mind.

3.2BuildUp Self-confidence on Children. Self-confidence is the first vital element toward success. A confident child tends to be optimistic and active, and dares to try new things or confront challenge. In this case, treating child as an independent individual functions as the premise of self-confidence cultivation. Parents should cast more encouragement than protection. Learning and exercising in practice can develop children's abilities, trigger their interest and foster their confidence. In the film Boyhood, Ted was very skilled at encouraging his child, whether in life or at study, that is to say, Ted didn't criticize Mason due to his poor performance, but positively encouraged Mason and inspired him to think about the life and made his own judgment. Moreover, Ted told Mason that he should believe in himself. He directly told that he was proud of him frequently.

3.3Create Equal and Democratic Family Atmosphere. Traditional Chinese family education concepts, such as obedience and docility, are the criteria for "good boy/girl", stifling their creativity [4]. The children only have answers like "No", "Yes" and "Ok" and cannot express their own ideas to their parents and pour forth their own feelings, which results into a stalemate parent-child relationship. In the film, there was a dialog among Ted, Samantha and Mason in a car on weekends. The first stepfather of Mason was a man who would like to control children and had domestic violence tendency. The children didn't want to and dare to communicate with his first stepfather and 
were unwilling to express their idea. Equality, dialogue, understanding and forgiveness shown in the film are the fundamental mechanism of morality, value and communication between different generations.

\section{Conclusion}

Education is an entire process for engagement in social life, and is also the key link among human being. Americans advocate individualism which emphasizes independence, creation, freedom and self-responsibility. American families pay more attention to human nature. It is vital to realize the differences on the family education, and our Chinese parents should offer democratic and optimistic environment for young children to develop self-determination, independence, confidence, and creativity.

\section{References}

[1] Pan Yueling, On American Family Education from Modern Family [J].Modern Enterprise Education. Shandong. 2014(20), p. 528

[2] Li Ying, The Enlightenment from American Family Education [J]. Forum on Contemporary Education. Beijing. 2004(10), p. 47

[3] Yang Wenlan, The Analysis of the Differences between Chinese and American Family Education from Premature and Juno [J]. Anhui Literature. Anhui. 2011(8), p. 74

[4] Zhang Xiaoliang, The Analysis of the Differences between Chinese and American Family Education [J]. Art and Literature for the Masses. Hebei. 2010(23), p. 269 